\title{
Escherichia coli aconitases and oxidative stress: post-transcriptional regulation of SodA expression
}

\author{
Yue Tang, Michael A. Quail, Peter J. Artymiuk, John R. Guest \\ and Jeffrey Green
}

The Krebs Institute for Biomolecular Research, Department of Molecular Biology and Biotechnology, University of Sheffield, Western Bank, Sheffield S10 2TN, UK

\author{
Author for correspondence: Jeffrey Green. Tel: +44 114 2224403. Fax: +44 1142728697. \\ e-mail : jeff.green@sheffield.ac.uk
}

\begin{abstract}
Escherichia coli possesses two aconitases, a stationary-phase enzyme (AcnA), which is induced by iron and oxidative stress, and a major but less stable enzyme (AcnB), synthesized during exponential growth. In addition to the catalytic activities of the holo-proteins, the apo-proteins function as posttranscriptional regulators by site-specific binding to acn mRNAs. Thus, it has been suggested that inactivation of the enzymes could mediate a rapidly reacting post-transcriptional component of the bacterial oxidative stress response. Here it is shown that $E$. coli acn mutants are hypersensitive to the redox-stress reagents $\mathrm{H}_{2} \mathrm{O}_{2}$ and methyl viologen. Proteomic analyses further revealed that the level of superoxide dismutase (SodA) is enhanced in acnB and acnAB mutants, and by exposure to methyl viologen. The amounts of other proteins, including thioredoxin reductase, 2-oxoglutarate dehydrogenase, succinyl-CoA synthetase and chaperone proteins, were also affected in the acn mutants. The altered patterns of sodA expression were confirmed in studies with sodA-lacZ reporter strains. Quantitative Northern blotting indicated that AcnA enhances the stability of the sodA transcript, whereas AcnB lowers its stability. Direct evidence that the apo-proteins have positive (AcnA) and negative (AcnB) effects on SodA synthesis was obtained from in vitro transcription-translation experiments. It is suggested that the aconitase proteins of $E$. coli serve as a protective buffer against the basal level of oxidative stress that accompanies aerobic growth by acting as a sink for reactive oxygen species and by modulating translation of the sodA transcript.
\end{abstract}

Keywords: protein-mRNA interactions, proteomics, iron-sulphur protein

\section{INTRODUCTION}

Aconitases (EC 4.2.1.4) catalyse the interconversion of citrate and isocitrate via cis-aconitate in the citric acid and glyoxylate cycles. They are monomeric enzymes that contain one $[4 \mathrm{Fe}-4 \mathrm{~S}]$ cluster that is essential for catalytic activity. The aconitase protein family contains aconitases, homoaconitases, isopropylmalate isomerases and iron regulatory proteins (IRPs), including the bifunctional IRP1/cytoplasmic aconitases (Gruer et al., 1997a). Escherichia coli contains two genetically and biochemically distinct aconitases, AcnA and AcnB,

Abbreviations: Acn, aconitase; IRP, iron regulatory protein; MV, methyl viologen; ODH, 2-oxoglutarate dehydrogenase; SCS, succinyl-CoA synthetase; SodA, superoxide dismutase; UTR, untranslated region. encoded by the acnA and $a c n B$ genes (Bradbury et al., 1996). Physiological and enzymological studies have shown that $A c n B$ is the major citric acid cycle enzyme synthesized during the exponential phase, whereas AcnA is a more stable stationary-phase enzyme, which is also specifically induced by iron and oxidative stress (Cunningham et al., 1997). The acnA gene is expressed from two promoters, P1 and P2. P1 is $\sigma^{38}$-dependent but otherwise unregulated, whereas $\mathrm{P} 2$ is a $\sigma^{70}$-dependent promoter that is also activated (directly or indirectly) by CRP (cAMP receptor protein), FruR, Fur and SoxRS, and repressed by ArcA and Fnr (Cunningham et al., $1997)$. The $a c n B$ gene has a single $\sigma^{70}$-dependent promoter that is activated by CRP and repressed by ArcA, FruR and Fis. Enzymological studies have indicated that Acn $A$ is adapted for maintaining citric acid cycle activity 
during exposure to (or recovery from) oxidative stress, whereas AcnB is adapted for the major catabolic role (Jordan et al., 1999).

In higher organisms, the cytoplasmic aconitases (cAcns) are remarkable bifunctional proteins that gain aconitase catalytic activity (c-Acn) by assembling [ $4 \mathrm{Fe}-$ $4 \mathrm{~S}$ ] clusters under conditions of iron sufficiency, but during iron-starvation and oxidative stress, when the clusters are disassembled, the catalytic activity is lost and the apo-proteins acquire site-specific RNA-binding activity (IRP1) (Beinert et al., 1996). The apo-proteins (IRP1s) recognize specific sequences [iron regulatory elements (IREs)], which form stem-loop structures at the $5^{\prime}$ or $3^{\prime}$ untranslated regions (UTRs) of relevant mRNA transcripts, such as ferritin and the transferrin receptor. Binding of IRP1 at the $5^{\prime}$ UTRs blocks translation, whereas binding at the 3' UTRs enhances translation by increasing transcript stability (Hentze \& Kuhn, 1996). The RNA binding activity of IRP1 increases in response to reagents such as $\mathrm{H}_{2} \mathrm{O}_{2}$, superoxide and nitric oxide, which induce oxidative stress, degrade the iron-sulphur clusters and hence inactivate the enzyme (c-Acn) and generate IRP1.

It has been shown that the aconitases of E. coli (AcnA and $A(n B)$ and the aconitase of B. subtilis (CitB) also have dual roles as enzymes and post-transcriptional regulators (Tang \& Guest, 1999; Alen \& Sonenshein, 1999). Apo-AcnA and apo-AcnB have each been shown to interact at physiological concentrations with the $3^{\prime}$ UTRs of $a c n A$ and $a c n B$ mRNA when their iron-sulphur clusters are oxidatively disassembled. Consequently, $A c n A$ and $A c n B$ synthesis is enhanced in vitro by the apo-Acns and this enhancement is abolished by deletion of the 3' UTRs from the DNA templates, presumably through loss of $a c n-m R N A$ stabilization by bound apoAcn. In B. subtilis aconitase has been shown to recognize a rabbit ferritin IRE and IRE-like sequences/structures in operons encoding cytochrome oxidase and an iron uptake system (Alen \& Sonenshein, 1999). Furthermore, a mutant strain expressing an enzymically inactive aconitase that retains RNA binding activity was able to sporulate more efficiently than an aconitase-null mutant, suggesting that aconitase has a non-enzymic role in sporulation (Alen \& Sonenshein, 1999). More recently, the E. coli AcnA and AcnB apo-proteins have likewise been shown to bind site-specifically to the rabbit ferritin IRE; previous failures to induce binding were attributed to the low range of protein concentrations used in earlier tests (Y. Tang \& J. R. Guest, unpublished observations). Analyses of virulence factor production in Pseudomonas aeruginosa (exotoxin $\mathrm{A}$ ) and Xanthomonas campestris have also indicated that aconitase might perform a regulatory role (Somerville et al., 1999; Wilson et al., 1998).

As stated above, the two aconitases of E. coli have been adapted for different physiological roles, but both are sensitive to conditions of oxidative stress mediated by superoxide and by nitric oxide (Gardner \& Fridovich, 1992; Gardner et al., 1997). Restoration of activity after nitric oxide treatment is inefficient, probably due to nitrosylation of the $[4 \mathrm{Fe}-4 \mathrm{~S}]$ cluster. However, after oxidation by oxygen aconitase activity can be efficiently restored by anaerobic reassembly of the iron-sulphur cluster. Thus, the two aconitase proteins of E. coli have the potential to serve as oxidative stress sensors through the reversible assembly/disassembly of their [4Fe-4S] clusters and the consequent interconversion between catalytic and RNA-binding functions. Furthermore, because of the different relative stabilities of the ironsulphur clusters of $A c n A$ and $A c n B$ the response can be poised at two levels, with AcnB sensing low/intermediate stress and AcnA reacting during exposure to severe stress. Here, the physiological and regulatory effects of acn mutations on the oxidative stress response of E. coli were investigated. It was found that acn mutants are hypersensitive to oxidative stress and that the synthesis of superoxide dismutase $(\operatorname{Sod} \mathrm{A})$ is positively regulated by apo-AcnA and negatively regulated by apo-AcnB.

\section{METHODS}

Bacterial strains, plasmids, proteins and basic methods. The strains of E. coli and the plasmids used in this study are listed in Table 1 . The $a c n A:: k a n^{\mathrm{R}}$ and $a c n B:: t^{\mathrm{R}}{ }^{\mathrm{R}}$ alleles were transferred from the W3110 derivatives JRG2789 and JRG3258, previously described by Gruer et al. (1997b), to MC4100 by $\mathrm{P} 1$ transduction. The authenticity of the selected transductants was verified by Southern blotting. The sodA-lacZ reporter strains, JRG3533-JRG3535a, were created by P1 transduction of $\Phi\left(\operatorname{sod} A-\right.$ lacZ) $49 \mathrm{Cm}^{\mathrm{R}}$ from QC772 (Carlioz \& Touati, 1986) into MC4100 and its acn derivatives. These transductants were confirmed by PCR using specific sodA and lacZ primers. The soxR mutation of DJ901 was transferred to JRG3533 [MC4100 $\Phi(\operatorname{sod} A-l a c Z) 49 \mathrm{Cm}^{\mathrm{R}}$ ] to create JRG4842, and to JRG3535 [MC4100 acnB $\Phi($ sodA-lacZ) $49 \mathrm{Cm}^{\mathrm{R}}$ ] to create JRG4843. The pUC119-based acnA phagemid (pGS447) contained the acnA-promoter and -coding regions in a $3 \cdot 2 \mathrm{~kb} \mathrm{BamHI-Pst}$ fragment (Prodromou et al., 1991). The pUC118-based $a c n B$ phagemid (pGS801) contains the promoter and coding regions of $a c n B$ in a $6.5 \mathrm{~kb} P v u \mathrm{II}$ fragment (Bradbury et al., 1996). Cultures containing the lac $Z$ reporter fusion were grown aerobically in L broth (Lennox, $1955)$ at $37^{\circ} \mathrm{C}$ to exponential phase $\left(\mathrm{OD}_{600} 0 \cdot 3\right)$ whereupon methyl viologen $(\mathrm{MV} ; 80 \mu \mathrm{M})$ was added to test cultures, but not to comparable controls, and incubation was continued for a further $1 \mathrm{~h}$ before sampling for $\beta$-galactosidase activity (Miller, 1972). The mean values of the specific activities (Miller units) from three independent experiments were obtained.

For testing sensitivity to $\mathrm{H}_{2} \mathrm{O}_{2}$, cultures were grown aerobically in L broth to exponential phase $\left(\mathrm{OD}_{600} \sim 0.3\right)$ and then exposed to $\mathrm{H}_{2} \mathrm{O}_{2}(4 \mathrm{mM})$ for 20,40 and $60 \mathrm{~min}$. $\mathrm{H}_{2} \mathrm{O}_{2}$ was removed by adding catalase $\left(1 \mathrm{mg} \mathrm{ml}^{-1}\right)$ to the medium. The cultures were diluted and then plated onto $\mathrm{L}$ agar $(16 \mathrm{~h}$ at $37^{\circ} \mathrm{C}$ ) to allow estimation of c.f.u. values. The effects of exposure to $\mathrm{MV}$ were tested by inoculating overnight cultures of MC4100 and its derivatives $(1: 1000)$ in fresh L broth with and without MV $(120 \mu \mathrm{M})$. Aerobic growth was then monitored by measuring the optical densities of these cultures at $600 \mathrm{~nm}$, and controls lacking MV, over an $8 \mathrm{~h}$ period.

DNA was prepared and manipulated by standard procedures (Sambrook et al., 1989). Total bacterial RNA was extracted from W3110 by the hot acid/phenol method (Aiba et al., 
Table 1. Strains of $E$. coli and plasmids

\begin{tabular}{|c|c|c|}
\hline Strain/plasmid & Relevant characteristics & Source/reference \\
\hline \multicolumn{3}{|l|}{ E. coli } \\
\hline W3110 & Prototroph & \\
\hline JRG2789 & W3110 acnA::kan ${ }^{\mathrm{R}}$ & Gruer et al. (1997b) \\
\hline JRG3258 & $\mathrm{W} 3110 a c n B:: t^{\mathrm{R}}{ }^{\mathrm{R}}$ & Gruer et al. (1997b) \\
\hline MC4100 & $\Delta l a c U 169$ rpsL & Silhavy et al. (1984) \\
\hline JRG3509 & MC4100 acnA : :kan ${ }^{\mathrm{R}}$ & This work \\
\hline JRG3510 & MC4100 acnB::tet $t^{\mathrm{R}}$ & This work \\
\hline JRG3511 & MC4100 acnA::kan ${ }^{\mathrm{R}} a c n B:: t e t^{\mathrm{R}}$ & This work \\
\hline JRG3511a & MC4100 acnA::kan ${ }^{\mathrm{R}} a c n B::$ tet $^{\mathrm{R}}$ glt $A$ & This work \\
\hline JRG3533 & MC4100 $\Phi(\operatorname{sod} A-l a c Z) 49 ; \mathrm{Cm}^{\mathrm{R}}$ & This work \\
\hline JRG3534 & MC4100 acnA $\Phi(\operatorname{sod} A-l a c Z) 49 ; \mathrm{Cm}^{\mathrm{R}}$ & This work \\
\hline JRG3535 & MC4100 acnB $\Phi(\operatorname{sod} A-l a c Z) 49 ; \mathrm{Cm}^{\mathrm{R}}$ & This work \\
\hline JRG3535a & MC4100 acnAB $\Phi(\operatorname{sod} A-l a c Z) 49 ; \mathrm{Cm}^{\mathrm{R}}$ & This work \\
\hline JRG4842 & MC4100 $\Delta \operatorname{soxR} \Phi(\operatorname{sodA}-l a c Z) 49 ; \mathrm{Cm}^{\mathrm{R}}, \mathrm{Km}^{\mathrm{R}}$ & This work \\
\hline JRG4843 & MC4100 $\Delta$ soxR acnB $\Phi(\operatorname{sod} A-l a c Z) 49 ; \mathrm{Cm}^{\mathrm{R}}, \mathrm{Km}^{\mathrm{R}}$ & This work \\
\hline DJ901 & $\Delta \operatorname{soxR} ; \mathrm{Km}^{\mathrm{R}}$ & Greenberg et al. (1990) \\
\hline QC772 & $\mathrm{F}^{-} \Delta l a c 4169 \operatorname{rpsL} \Phi(\operatorname{sod} A-l a c Z) 49 ; \mathrm{Cm}^{\mathrm{R}}$ & Carlioz \& Touati (1986) \\
\hline \multicolumn{3}{|l|}{ Plasmid } \\
\hline pGS447 & pUC119 $a c n A^{+} ; \mathrm{Ap}^{\mathrm{R}}$ & Prodromou et al. (1991) \\
\hline pGS801 & pUC118 $a c n B^{+} ; \mathrm{Ap}^{\mathrm{R}}$ & Bradbury et al. (1996) \\
\hline
\end{tabular}

1981). The RNA ( $100 \mu \mathrm{g})$ was resuspended in $50 \mu$ l of buffer containing $20 \mathrm{mM}$ Tris $/ \mathrm{HCl}(\mathrm{pH} 8 \cdot 0), 10 \mathrm{mM} \mathrm{MgCl}, 1 \mathrm{mM}$ DTT and $10 \%(\mathrm{v} / \mathrm{v})$ glycerol before adding RNase-free DNase I $(20 \mathrm{U})$ and incubating at $37^{\circ} \mathrm{C}$ for $30 \mathrm{~min}$ to remove traces of DNA. The RNA was then isolated by phenol extraction followed by ethanol precipitation. Aconitase holoproteins and apo-proteins were prepared according to Tang \& Guest (1999).

Proteomic analyses. Cultures (in $10 \mathrm{ml}$ of L broth) of MC4100 (parent), JRG3509 (acnA), JRG3510 (acnB) and JRG3511 $(a c n A B)$ were grown with vigorous shaking (250 r.p.m.) in $100 \mathrm{ml}$ flasks at $37^{\circ} \mathrm{C}$ to exponential phase $\left(\mathrm{OD}_{600} 0 \cdot 8-1 \cdot 0\right)$. The bacteria were then either harvested or, where stated, their transcription was arrested by adding rifampicin $\left(0 \cdot 2 \mathrm{mg} \mathrm{ml}^{-1}\right)$ immediately prior to adding MV $(0.3 \mathrm{mM})$. Incubation was then continued for a further $60 \mathrm{~min}$. The harvested bacteria were resuspended in $20 \mathrm{mM}$ Tris $/ \mathrm{HCl}(\mathrm{pH} \mathrm{7 \cdot 3)}$ for ultrasonic disruption and cell-free supernatant extracts were recovered by centrifugation at $14000 \mathrm{~g}$ for $10 \mathrm{~min}$ at $4{ }^{\circ} \mathrm{C}$ and stored at $-20^{\circ} \mathrm{C}$. Protein contents were assayed by the Bio-Rad method, with bovine serum albumin as the standard, and samples containing $100 \mu \mathrm{g}$ protein were applied to immobilized $\mathrm{pH}$ gradient strips $(110 \mathrm{~mm}$ in length; a linear $\mathrm{pH} 4-7$ gradient, Amersham Pharmacia) for fractionation in the first dimension. Second-dimension fractionation was performed with ExcelGel SDS 8-18\%, using a Pharmacia Multiphor II electrophoresis unit. In preliminary experiments pairs of identical gels were either stained with Coomassie blue R-250 for protein visualization or electroblotted onto ProBlott membranes for protein identification by N-terminal-aminoacid sequencing. In subsequent experiments, stained gels were analysed using ImageMaster 3.01 software (Amersham Pharmacia) and polypeptide spots that varied in intensity by at least $2 \cdot 5$-fold due to redox stress or to strain differences were excised, destained and digested with trypsin prior to peptide analysis by mass spectrometry. The MASCOT program was used to identify proteins from their peptide profiles.
Northern blotting and mRNA half-life. The effects of MV on $\operatorname{sod} A$ mRNA content and stability were studied with equivalent exponential-phase cultures of parental and acn strains. Rifampicin $\left(200 \mu \mathrm{g} \mathrm{ml}^{-1}\right)$ was added $10 \mathrm{~min}$ after the addition of MV $(0.3 \mathrm{mM})$; samples were then taken after a further 0,2 , 5,10 and $20 \mathrm{~min}$, and chilled immediately in liquid $\mathrm{N}_{2}$ for RNA extraction and quantitative Northern analysis. RNA $(25 \mu \mathrm{g})$ was separated in a $1 \%$ agarose/formaldehyde gel (Sambrook et al., 1989), denatured and then transferred to a Hybond-N membrane (Amersham Pharmacia) for hybridization using a sodA probe labelled with $\left[\alpha^{32} \mathrm{P}\right] \mathrm{dCTP}$ [3000 $\mathrm{Ci} \mathrm{mmol}^{-1}\left(111 \mathrm{TBq} \mathrm{mmol}^{-1}\right)$; NEN] according to the manufacturer's instructions ('Ready to Go' Labelling Kit; Amersham Pharmacia). The probe, containing the entire sodA-coding region flanked by two $300 \mathrm{bp}$ segments, was PCR-amplified from E. coli W3110 chromosomal DNA. The relative amounts of sodA mRNA in each RNA sample and their corresponding half-lives were determined by direct analysis of the blot using a Packard Instant Imager with Electronic Autoradiography software (version 2.01).

In vitro transcription-translation. Plasmid DNA (pGEM-T containing the sodA-coding region and $300 \mathrm{bp}$ of upstream and downstream sequences from W3110 genomic DNA) or linear DNA amplified from the pGEM-T sodA plasmid with the Boehringer Expand High Fidelity PCR System $(1 \mu \mathrm{g})$ was mixed with $3.75 \mu \mathrm{l} \mathrm{S} 30$ extract for linear templates (Promega), $0 \cdot 25 \mu \mathrm{l}\left[{ }^{35} \mathrm{~S}\right]$ methionine $\left[1000 \mathrm{Ci} \mathrm{mmol}{ }^{-1}\left(37 \mathrm{TBq} \mathrm{mmol}^{-1}\right)\right.$; ICN], $1 \cdot 25 \mu \mathrm{l}$ amino acid mixture minus methionine, $5 \mu \mathrm{l} \mathrm{S} 30$ premix, apo-aconitase $(0 \cdot 2$ and $2 \cdot 0 \mu \mathrm{M}$ final concentration prepared according to Tang \& Guest, 1999) and $\mathrm{H}_{2} \mathrm{O}$ to $12.5 \mu \mathrm{l}$, before incubating at $37^{\circ} \mathrm{C}$ for $90 \mathrm{~min}$. Translation products were precipitated with $50 \mu$ lacetone and resuspended in loading buffer for SDS-PAGE separation, autoradiography and quantitative analysis of ${ }^{35} \mathrm{~S}$-labelled components excised from the gels and counted in vials containing $3 \mathrm{ml}$ of Safefluor S (Lumac-LSC) using a Beckman LS 1801 Liquid Scintillation System. 


\section{RESULTS}

\section{acn mutations confer sensitivity to peroxide stress}

Previous studies indicated that the iron-sulphur clusters of the aconitase proteins of E. coli (AcnA and AcnB) are disassembled in response to oxidative stress, which converts the enzymes into mRNA-binding proteins (Tang \& Guest, 1999). It was therefore suggested that specific interactions between aconitase apo-proteins and relevant transcripts could provide a rapidly reacting component of the bacterial response to oxidative stress.

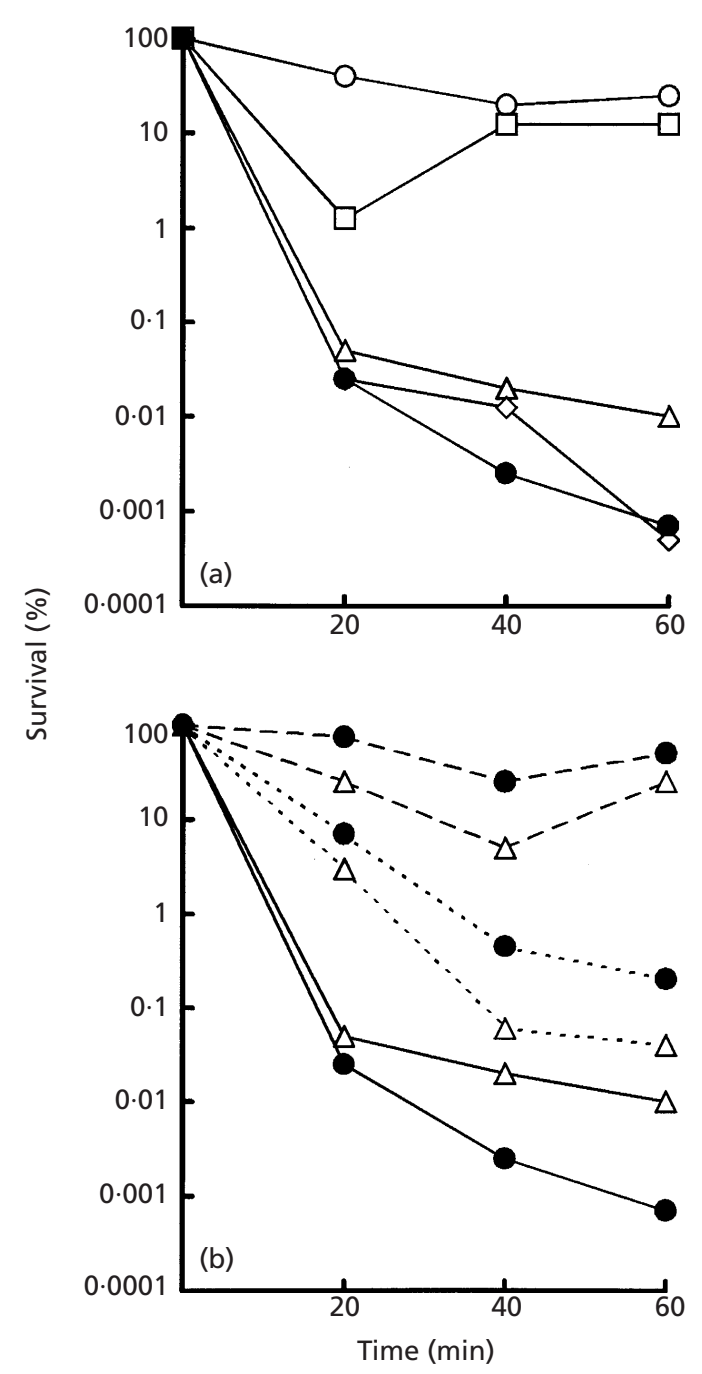

Fig. 1. Survival kinetics of acn mutants after exposure to $\mathrm{H}_{2} \mathrm{O}_{2}$. Typical survival curves are shown for exponential-phase cultures challenged with $\mathrm{H}_{2} \mathrm{O}_{2}(4 \mathrm{mM})$ for the indicated periods of time. The survival (\%) was estimated by plating serial dilutions of each culture on L agar before and after treatment, and counting numbers of c.f.u. after incubation for $16 \mathrm{~h}$ at $37^{\circ} \mathrm{C}$. (a) O. MC4100 (AcnA ${ }^{+}$AcnB $^{+}$GltA $^{+}$; wild-type); $\square$, JRG3509 $\left.\left(\operatorname{acn} A:: \operatorname{kan}^{\mathrm{R}}\right) ; \quad \triangle, \quad J R G 3510 \quad\left(a c n B:: t^{\mathrm{R}}\right)^{\mathrm{R}}\right) ; \diamond, \quad J R G 3511$ $\left.\left(\Delta a c n A:: k_{a n}^{R} \text { acnB::tet }\right)^{R}\right)$, JRG3511a (acnA::kan ${ }^{R}$ acnB::tet ${ }^{R}$ gltA). (b) Transformants of JRG3510 (acnB::tet $\left.t^{R}\right)(\triangle)$ and JRG3511a (acnA : :kan ${ }^{\mathrm{R}}$ acnB::tet $\left.{ }^{\mathrm{R}} \mathrm{glt} A\right)(\mathbf{O})$ containing pGS447 $\left(A \subset n A^{+}\right.$; dotted lines), pGS801 (AcnB'; dashed lines) and untransformed hosts (solid lines).
If true it would mean that acn mutants should be more sensitive to such stress. Accordingly, acnA and $a c n B$ single and double mutants were challenged with $4 \mathrm{mM}$ $\mathrm{H}_{2} \mathrm{O}_{2}$. The parental strain (MC4100) survived the challenge well, with $\sim 25 \%$ survival after $60 \mathrm{~min}$; the acn $A$ mutant was only marginally more sensitive, with $13 \%$ survival after $60 \mathrm{~min}$ (Fig. 1a). In marked contrast the $a c n B$ mutant was very sensitive, with viability falling to $<0.1 \%$ after only $20 \mathrm{~min}$ and to $<0.01 \%$ after $60 \mathrm{~min}$ exposure (Fig. 1a). The $a c n A$ acnB double mutant was even more sensitive, with only $<0.001 \%$ survival after $60 \mathrm{~min}$ (Fig. 1a). To investigate the possibility that citrate accumulation might contribute to the hypersensitivity of the double mutant, a triple mutant (JRG3511a; acnA acnB gltA), which can neither accumulate nor metabolize citrate because it lacks citrate synthase as well as aconitase, was tested. No lowering of peroxide sensitivity was conferred by the citrate synthase (glt $A$ ) lesion, indicating that citrate accumulation does not contribute significantly to the enhanced peroxide-sensitivity of the $a c n A B$ double mutant. High-copy-number plasmids expressing the acn genes from the natural promoters were used in complementation tests. These showed that the effects of the $a c n B$ lesion were almost fully complemented by the $a c n B$ plasmid (pGS801), whereas the acnA plasmid (pGS447) was far less effective (Fig. 1b). A similar pattern of complementation was observed with the acnA acnB glt $A$ triple mutant (JRG3511a), where the acnB plasmid restored a wild-type response to peroxide but the acnA plasmid afforded only partial complementation (Fig. 1b). Although the differences in plasmid efficacy might reflect differential control of the $a c n A$ and $a c n B$ promoters, as well as other features related to enzyme sensitivities and their post-transcriptional regulatory functions, it would appear that $A \mathrm{cnB}$ is more important than AcnA in resisting oxidative stress in these exponential phase cultures. It is also interesting but equally unclear why the degree of complementation mediated by both plasmids was greater in the triple mutant than in the $a c n B$ mutant (Fig. 1b). Nevertheless, it is clear that peroxide hypersensitivity is not due to the lack of citric acid cycle function per se, because the $a c n B$ plasmid restored a wild-type response to peroxide exposure in the triple mutant without restoring citrate synthase activity. It was therefore concluded that $A c n B$ and, to a lesser extent, AcnA perform an important role in resisting peroxide stress in exponential-phase cultures.

\section{A double acnA acnB lesion confers hypersensitivity to MV}

The effects of acn mutations on the oxidative-stress tolerance of E. coli were extended to include the redoxcycling agent $\mathrm{MV} . \mathrm{MV}$ is reduced by at least three oxidoreductases to generate a one-electron reduced form that spontaneously reacts with oxygen to generate superoxide. As the initial reduction of $M V$ requires NADPH the pool of reduced nicotinamide cofactors is simultaneously depleted. The final culture densities reached by the parental strain and the $a c n A$ and $a c n B$ 

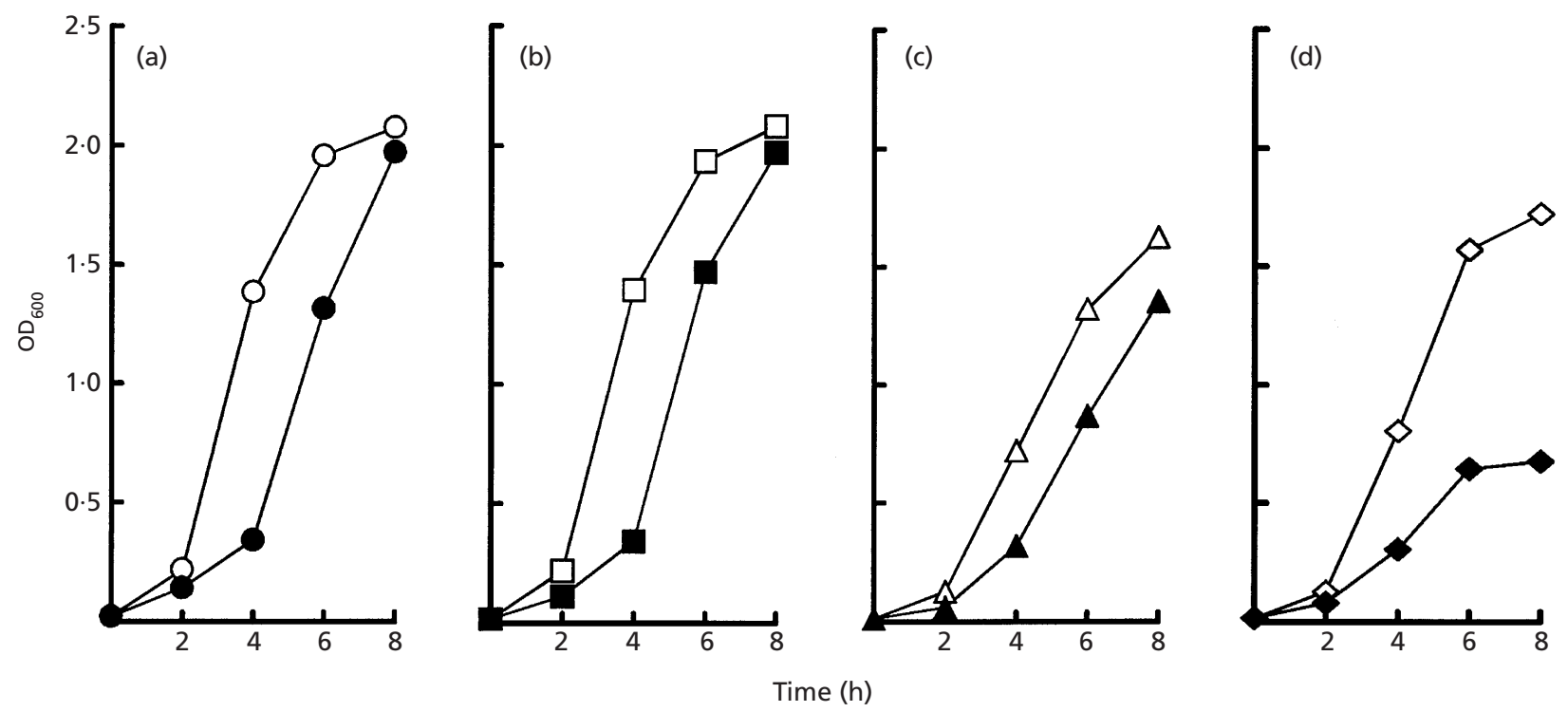

Fig. 2. Effects of MV on the growth of acn mutants. Cultures were grown aerobically in L broth without MV (open symbols) and with $120 \mu \mathrm{M}$ MV (solid symbols). (a) MC4100 (AcnA ${ }^{+}$AcnB $^{+}$); (b) JRG3509 (acnA::kan ${ }^{R}$; (c) JRG3510 $\left(a c n B:: t^{R} t^{R}\right.$; (d) JRG3511 (acnA : : $\operatorname{kan}^{R}$ acnB : : tet $\left.{ }^{R}\right)$.

single mutants in the presence or absence of MV were similar, despite the increased lag in the latter cultures (Fig. 2). However, MV severely limited the growth of the acn $A B$ double mutant (Fig. 2). This suggests that AcnA and $A c n B$ are both involved in resisting the effects of MV-induced stress and that AcnA can compensate for the lack of AcnB, and vice versa. Alternatively, the sensitivity of the double mutant may be caused by an inability to correct an $\mathrm{MV}$-induced imbalance in the $\mathrm{NAD}(\mathrm{P}) \mathrm{H}: \mathrm{NAD}(\mathrm{P})^{+}$pools, due to the absence of a functional citric acid cycle.

\section{Proteomic analysis of acn mutants}

Having shown that E. coli acn mutants are hypersensitive to $\mathrm{H}_{2} \mathrm{O}_{2}$ and $\mathrm{MV}$, we used proteomic analysis to investigate the changes in protein expression that might be associated with the increased sensitivity. In preliminary experiments, the protein profiles of unstressed aerobic mid-exponential-phase cultures of wild-type, $a c n A$ and $a c n B$ strains were compared. No significant differences were detected between the $a c n A$ mutant and the parental strain, as might have been predicted, because $a c n A$ is only expressed during stationary phase or under conditions of oxidative stress (Gruer \& Guest, 1994). In contrast, the amounts of at least 11 polypeptides were altered in the $a c n B$ mutant and four were identified by $\mathrm{N}$-terminal-amino-acid sequence analysis as: 2-oxoglutarate dehydrogenase $(\mathrm{ODH}, \mathrm{E} 1$ component); dihydrofolate reductase; YedA (a $32 \cdot 2 \mathrm{kDa}$ hypothetical protein; Swiss-Prot accession no. P09185); and, most interesting in the current context, a key component of the armoury of E. coli for combating oxidative stress, SodA, which was increased approximately fivefold. Some of the differences in the $a c n B$ protein profile probably reflect metabolic adaptations associated with the lack of a key enzyme rather than being related to the oxidative stress response.

In subsequent experiments, the effects of adding MV to each strain were investigated. Moreover, rifampicin was added to stressed and unstressed cultures in order to arrest transcription and thus to improve the detection of changes potentially stemming from the post-transcriptional (mRNA-binding) activities of the apo-aconitases. Representative protein profiles from redox-stressed cultures of the parent and $a c n B$ strains are shown in Fig. 3. Quantitative pairwise comparisons of the profiles of redox-stressed and unstressed cultures of each strain revealed a total of 17 polypeptides that both varied at least $2 \cdot 5$-fold under stress or between strains and were identifiable by tryptic digestion and mass spectrometry (Table 2). Again there was a marked increase in SodA production by the $a c n B$ mutant and also in the direct response to redox stress in other strains (Table 2; Fig. 3). Hence, the SodA content increased $4 \cdot 8$-fold in the parental strain and threefold (to the same level) in the acnA mutant when exposed to MV (Table 2). However, consistent with the preliminary findings, the $a c n B$ mutant produced ninefold more SodA than its parent in the absence of $\mathrm{MV}$, reaching a level that was almost twice the level of SodA achieved by redox-stressed cultures of the parental and acnA strains (Table 2). It was also apparent that despite having a relatively high level of SodA, the $a c n B$ mutant strain could still produce more under redox-stress conditions (Table 2). The SodA profile of the acnA acnB double mutant resembled that of the $a c n B$ mutant in having an elevated basal level of SodA, but it no longer appeared to be further enhanced by redox stress conditions.

The synthesis of several other proteins appeared to be specifically perturbed by the acn lesions or by redox 


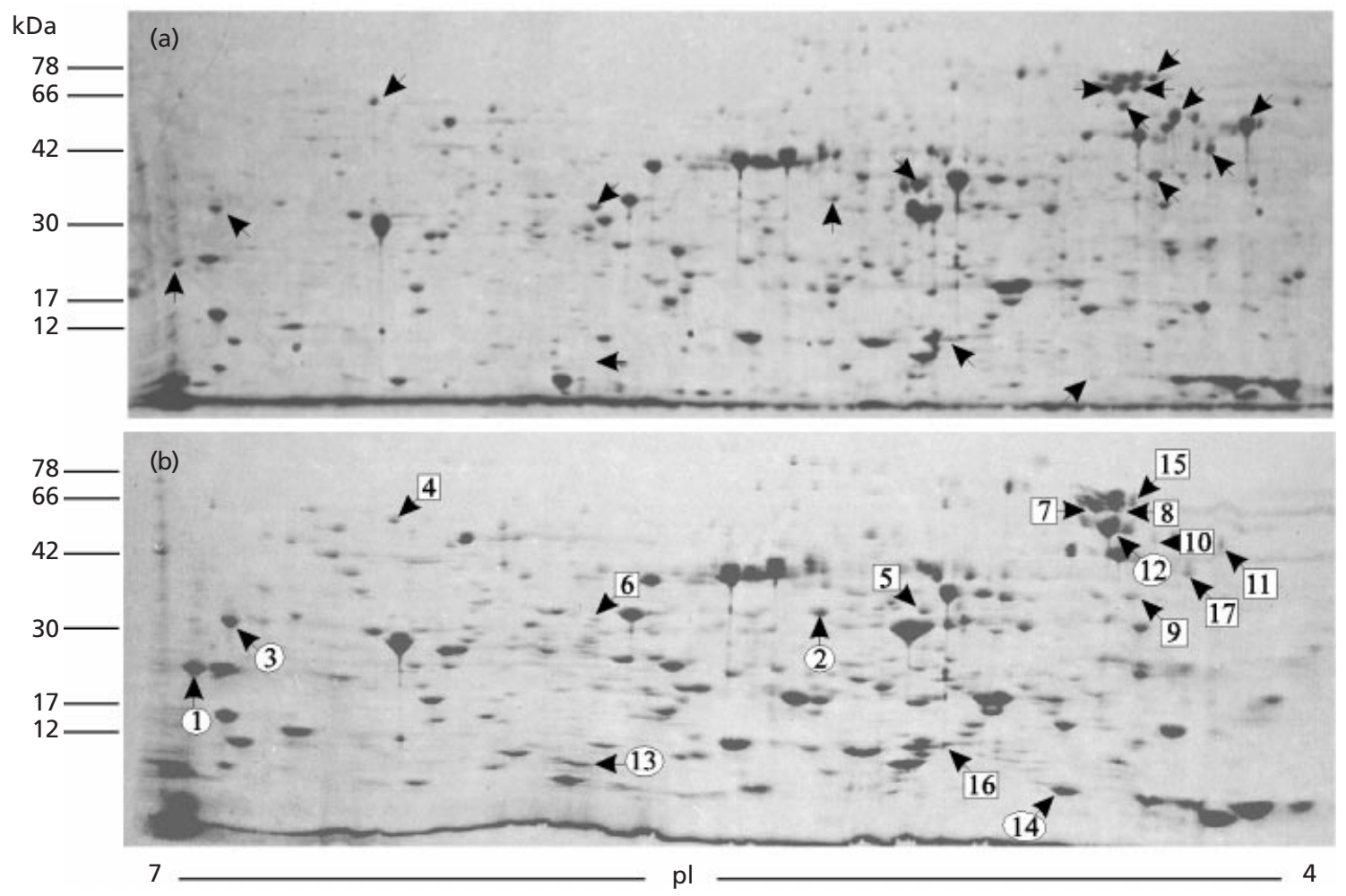

Fig. 3. Representative protein profiles of parent and mutant strains. Cultures were grown aerobically to mid-exponential phase $\left(\mathrm{OD}_{600} 0.8\right)$ before adding rifampicin $\left(0.2 \mathrm{mg} \mathrm{ml}^{-1}\right)$ and $\mathrm{MV}(0.3 \mathrm{mM})$ and incubation for a further $1 \mathrm{~h}$. Protein profiles of (a) the parental strain, MC4100, and (b) the isogenic acnB mutant, JRG3510, are shown. The arrows and numbers denote the proteins that both vary significantly between the parent and the mutant on visual inspection and were positively identified by mass spectrometry (as listed in Table 2). Encircled and boxed numbers denote proteins that appeared to be either more or less abundant, respectively, in the acnB mutant.

stress. For example, the pattern of thioredoxin reductase (TrxB) production resembled that of SodA, except that the intracellular level of $\operatorname{TrxB}$ was also elevated in the acnA mutant compared to that of the parental strain (Table 2). TrxB is involved in maintaining the reduced status of the cytoplasm and hence protecting cells from oxidative damage, particularly by preventing the formation of protein disulphides. So the results indicate that the $a c n$ lesions are associated with enhanced production of anti-oxidative-stress proteins. Changes were detected in two unidentified proteins, YggX and YedA, and it may be significant that the former is encoded in a putative $m u t Y-y g g X-m t l C$ operon, because MutY is an essential component of a base excision-repair system that protects against the incorporation of a guanine oxidation product, 7,8-dihydro-8-oxoguanine, and may thus have a role in DNA repair following oxidative damage (Gifford \& Wallace, 1999).

Other changes included the lowering of chaperone protein levels (GroEL, DnaK and Tig) in the $a c n B$ mutant strain (Table 2). This implies that protein folding problems may arise when AcnB is absent. In the same context the modulations of oligopeptide-binding protein
(OppA) and maltose-binding protein (MalE) synthesis may be related to protein folding, because both have been shown to interact with unfolded proteins, to promote the functional folding of citrate synthase and $\alpha$-glucosidase, and to prevent aggregation of citrate synthase under heat shock conditions (Richarme \& Caldas, 1997). Alternatively, proteins such as MalE, OppA, ODH and succinyl-CoA synthetase (SCS; $\beta$ subunit) that participate in substrate transport and the citric acid cycle may be responding to the absence of a fully functional citric acid cycle.

The greatly enhanced level of HdeB in the $a c n B$ mutant is interesting because $\mathrm{HdeB}$ is a periplasmic protein that may be involved in acid resistance. Its expression is enhanced in stationary phase and repressed by H-NS (Yoshida et al., 1993; Holland et al., 1999) and the pattern of expression observed here suggests that AcnA (the stationary-phase enzyme) has a positive effect on HdeB synthesis, consistent with the view that Acn proteins assist in co-ordinating a stress response. Finally, the RpsA contents are lowered in all of the acn mutants (Table 2). RpsA is a component of the $30 \mathrm{~S}$ ribosomal subunit that is essential for the efficient translation of 
Table 2. Identifiable polypeptides which have expression profiles that vary under redoxstress conditions or between parent and acn strains

The relative abundances of proteins in Coomassie-blue-stained gels from aerobic cultures of strains grown in the absence $(-\mathrm{MV})$ or presence $(+\mathrm{MV})$ of $\mathrm{MV}(0.3 \mathrm{mM})$ were quantified using ImageMaster software and identified as described in Methods. Values were normalized between strains with respect to a collection of invariant proteins.

\begin{tabular}{|c|c|c|c|c|c|c|c|c|c|}
\hline \multirow[t]{3}{*}{ Protein } & & \multicolumn{8}{|c|}{ Culture conditions } \\
\hline & & \multicolumn{4}{|c|}{$-\mathrm{MV}$} & \multicolumn{4}{|c|}{$+\mathrm{MV}$} \\
\hline & & $\mathrm{Acn}^{+}$ & $\operatorname{acn} A$ & $a c n B$ & $\operatorname{acn} A B$ & $\mathrm{Acn}^{+}$ & $\operatorname{acn} A$ & $a c n B$ & $\operatorname{acn} A B$ \\
\hline 1 & SodA & 13 & 21 & 118 & 85 & 62 & 64 & 141 & 91 \\
\hline 2 & $\operatorname{TrxB}$ & 15 & 38 & 25 & 46 & 53 & 37 & 72 & 81 \\
\hline 3 & SCS & 88 & 35 & 117 & 37 & 77 & 49 & 185 & 42 \\
\hline 4 & OppA & 6 & 20 & 7 & 14 & 35 & 35 & 28 & 18 \\
\hline 5 & MalE & 206 & 102 & 18 & 123 & 185 & 92 & 23 & 89 \\
\hline 6 & $\mathrm{NanA}$ & 48 & 72 & 8 & 24 & 78 & 68 & 26 & 27 \\
\hline $7-8$ & RpsA & 460 & 99 & 176 & 232 & 325 & 266 & 275 & 151 \\
\hline $9-12$ & GroEL & 808 & 480 & 384 & 263 & 553 & 548 & 371 & 369 \\
\hline 13 & YggX & 35 & 38 & 127 & 48 & 48 & 64 & 115 & 18 \\
\hline 14 & HdeB & 28 & 15 & 136 & 9 & 6 & 22 & 143 & 14 \\
\hline 15 & DnaK & 45 & 48 & 21 & 47 & 52 & 51 & 19 & 33 \\
\hline 16 & AsnS† & 24 & 51 & 19 & 97 & 46 & 36 & 31 & 86 \\
\hline 17 & Tig & 67 & 45 & 25 & 54 & 88 & 38 & 22 & 88 \\
\hline
\end{tabular}

*Proteins highlighted in bold have, or may have, functions related to oxidative stress.

† The observed AsnS protein is a processed form with a molecular mass of approximately $12000 \mathrm{Da}$ rather than $52439 \mathrm{Da}$.

most bacterial transcripts and it negatively autoregulates translation probably by interacting with its own transcript (Skouv et al., 1990; Boni et al., 2000) - not unlike the aconitases (Tang \& Guest, 1999). Hence, translation of rpsA mRNA is geared to ribosome synthesis because the former is inhibited by excess RpsA subunits. The lower levels of RpsA in acn mutants suggest that overall translation activity may be reduced in these mutants, and thus the increase in SodA and $\operatorname{TrxB}$ contents is all the more significant. This may be linked in some unknown manner to the increased levels of asparaginyltRNA synthetase (AsnS), N-acetylneuraminate lyase and dihydrofolate reductase.

From the proteomic studies, it was concluded that acn lesions affect the production of proteins associated with the oxidative-stress response, central metabolism, acid stress, protein translation, protein folding and DNA repair. Indeed, the overall pattern of changes suggests that the mutant profiles resemble those exhibited by the parental strain after exposure to oxidative stress. Also, it appeared that in particular AcnA and AcnB directly or indirectly affect the synthesis of SodA, even in the absence of transcription.

\section{Studies with a sodA-lacZ translational fusion}

Further studies on the effects of acn lesions on SodA synthesis were made with the isogenic series of MC4100 $(\Delta l a c)$ derivatives containing $a c n A$ and $a c n B$ mutations

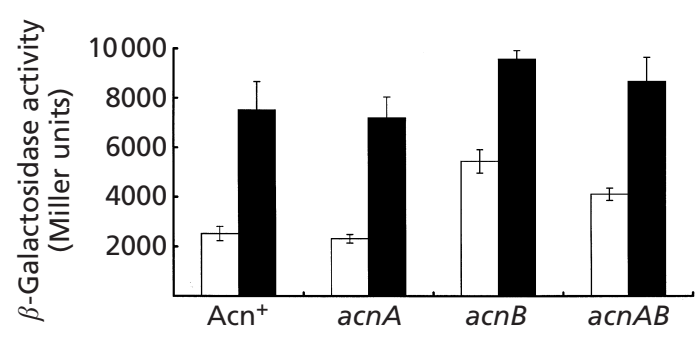

Fig. 4. Expression of a sodA-lacZ reporter in isogenic parent and acn strains. The expression of sodA was monitored by measuring the $\beta$-galactosidase activities of aerobic cultures of the sodA-lacZ reporter strains JRG3533 $\left(\mathrm{Acn}^{+}\right)$, JRG3534 (acnA), JRG3535 (acnB) and JRG3535a (acnAB) during the exponential phase of growth. The effects of adding MV $(80 \mu \mathrm{M})$ for $1 \mathrm{~h}$ prior to estimating sodA expression were also determined. Without MV, open bars; with MV, filled bars. The $\beta$-galactosidase activities derived from three independent experiments are shown \pm SD.

and a $\operatorname{sodA-lacZ}$ translational fusion (Table 1). Expression of sodA-lacZ in exponential cultures of the parental strain was approximately threefold higher when MV was added (Fig. 4). Exactly the same expression profiles were observed for $\operatorname{sod} A$ expression in the acnA mutant (Fig. 4). However, in unstressed cultures of the $a c n B$ mutant, sodA expression approached that of the stressed parental cultures and was 

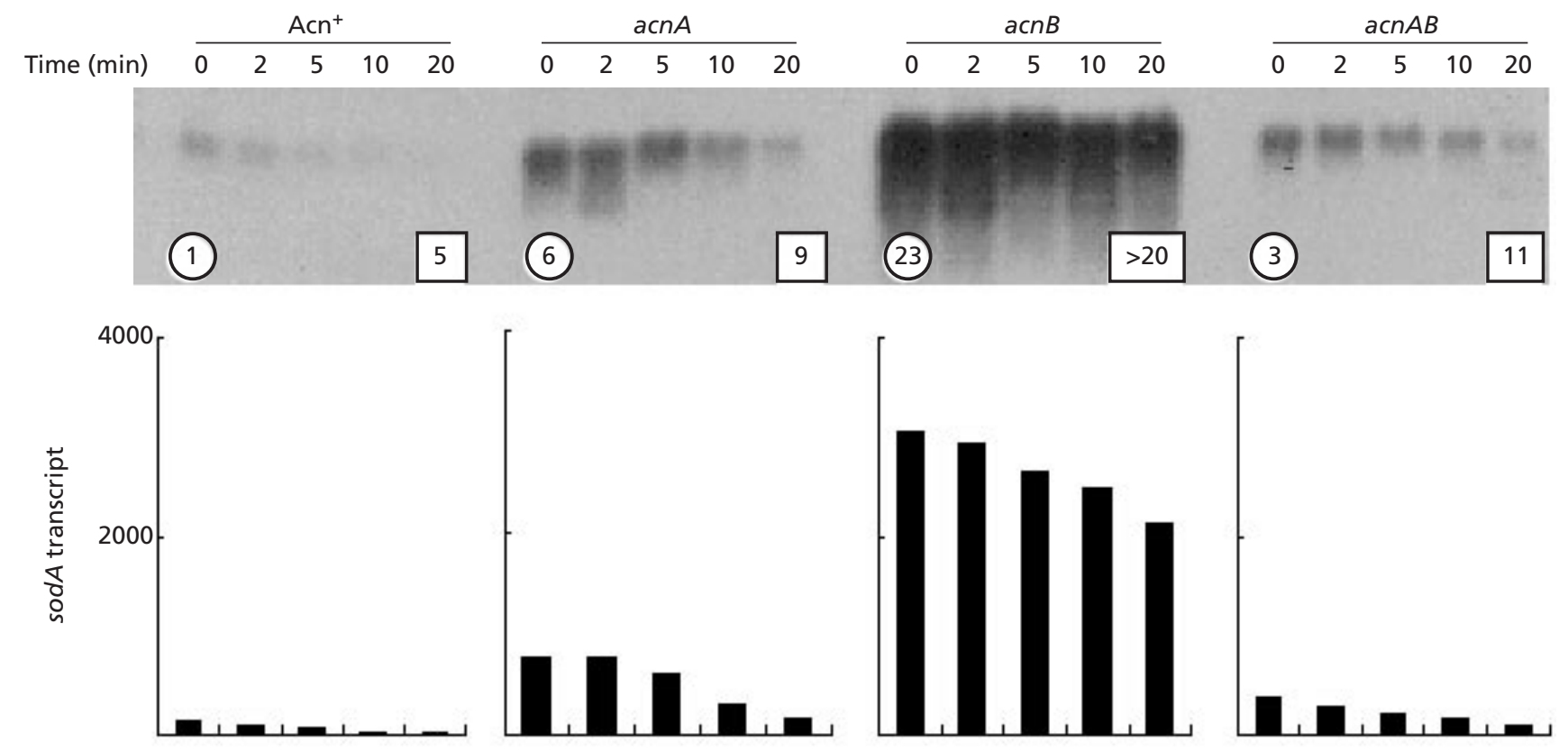

Fig. 5. Northern blot analyses of the sodA transcript in isogenic parent and acn strains. Northern blots of sodA mRNA from aerobic exponential phase cultures of W3110 and the corresponding acn mutants (Table 1). Rifampicin $\left(0.2 \mathrm{mg} \mathrm{ml}^{-1}\right.$ ) was added to all of the cultures to arrest transcription and to reveal differences in sodA mRNA stability. The amounts of sodA mRNA were calculated from the extents of hybridization of the radioactive probe, detected by a Packard Instant Imager and processed by Electronic Autoradiography software. The values for each zero-time sample relative to that of the parental strain (131 $\mathrm{U}$ after $20 \mathrm{~h}$ counting) are shown in circles and the half-lives (min) are indicated in squares. Plots showing the quantification of the sodA transcript in the same units are provided in the corresponding charts.

enhanced a further $\sim 1.5$-fold by adding MV (Fig. 4). Compared to the $a c n B$ mutant $\operatorname{sod} A$ expression was lower than in comparable cultures of the $a c n A B$ double mutant, but not as low as in cultures of the parental or acnA strains (Fig. 4). The pattern of sodA expression in exponential-phase cultures was consistent with the proteomic analysis and it indicates that both aconitase proteins affect SodA synthesis either directly or indirectly, but in opposite directions. Relative to the baseline provided by the double mutant it appears that AcnA enhances sodA expression, whereas $A c n B$ is inhibitory, possibly via an inhibitory interaction between apo-AcnB and the $5^{\prime}$ UTR of the sodA transcript. Furthermore, it would appear that in the parental strain the positive influence of AcnA is completely masked by the negative regulatory effects of AcnB. Any enhancement that might normally stem from Acn interaction with the 3' UTR of the sodA transcript would not be observed in these experiments because this region is deleted from the sodA-lacZ reporter.

The strains JRG3533 ( $\operatorname{sodA-lacZ),~JRG3535~(sodA-~}$ lacZ $\Delta a c n B)$, JRG4842 (sodA-lacZ $\Delta \operatorname{soxR})$ and JRG4843 (sodA-lacZ $\Delta$ soxR $\Delta a c n B)$ were used to test whether the enhanced expression of $\operatorname{sod} A$ in the $a c n B$ mutant was fully or partially dependent on SoxR. The results indicated that the soxR lesion reduced expression of $\operatorname{sodA}-\mathrm{lac} Z$ in aerobic exponential-phase cultures: $790 \pm 40$ Miller units for JRG4842 ( $\Delta$ soxR) compared to $2525 \pm 290$ Miller units for JRG3533 $\left(\right.$ SoxR $\left.^{+}\right)$. Fur- thermore, consistent with the interpretation of the proteomic and sodA-lacZ expression data reported above (Table 2; Fig. 4), sodA-lacZ expression was enhanced in the $\Delta$ soxR $\triangle a c n B$ strain: $4440 \pm 260$ Miller units for JRG4843 ( $\Delta$ soxR $\Delta a c n B)$, compared to $790 \pm 40$ Miller units for JRG4842 $\left(\Delta \operatorname{soxR} \mathrm{AcnB}^{+}\right)$. However, the level of expression for JRG4843 ( $\Delta \operatorname{soxR} \Delta a c n B$ ) was still lower than the $5440 \pm 475$ Miller units obtained with equivalent cultures of JRG3535 (SoxR $\left.{ }^{+} \Delta a c n B\right)$. These observations suggest that the enhanced expression of sodA-lacZ in an $a c n B$ mutant is mostly due to the absence of apo-AcnB-mediated post-transcriptional regulation and is only partially dependent on transcription activation by SoxR.

\section{Synthesis and stability of sodA mRNA}

A remarkable feature of the apo-Acn proteins of E. coli is their ability to interact specifically with the $3^{\prime}$ UTRs of both acn transcripts, thereby increasing translation and the intracellular contents of the Acn proteins by protecting the acn transcripts (Tang \& Guest, 1999). To investigate whether aconitase-mediated post-transcriptional regulation contributes to the changes in SodA content, revealed by the proteomic and sodA-lacZ fusion studies, the amounts and half-lives of $\operatorname{sod} A$ mRNA were compared in acn mutant and parental strains. Northern blotting showed that the sodA transcript increased 23 -fold in the $a c n B$ mutant compared to 
the parent (Fig. 5). The relative amounts of sodA mRNA also increased six- and threefold in the $\operatorname{acn} A$ and $a c n A B$ mutants, respectively. The half-lives of the sodA transcripts likewise increased from $5 \mathrm{~min}$ in the parental strain to 9,11 and $>20 \mathrm{~min}$ in the $\operatorname{acn} A, a c n A B$ and $a c n B$ mutants, respectively (Fig. 5). Hence, it would appear that the $\operatorname{sod} A$ transcript has a greatly increased half-life and is consequently more abundant in the $a c n B$ mutant than in the other strains. The relative amounts of $\operatorname{sod} A$ transcript matched the levels of the $\operatorname{sod} A-l a c Z$ expression exhibited by the corresponding unstressed fusion strains (Fig. 4), at least insofar as the values for the $a c n B$ mutant were higher than those of the $a c n A B$ double mutant. Moreover, all of the strains responded to $\mathrm{MV}$ by increasing their sodA mRNA contents, the relative increases being greatest with the parental strain and least with the $a c n B$ mutant (not shown), which also

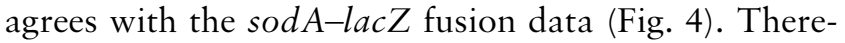
fore, the results indicate that, either directly or indirectly, AcnB reduces the stability of $\operatorname{sod} A$ transcripts and that at least one factor contributing to the increased expression of $\operatorname{sod} A$ in the $a c n B$ mutant is likely to be mRNA stabilization.

\section{Effects of apo-Acn proteins on SodA synthesis in vitro}

The data presented above indicate that the aconitases can influence the synthesis of proteins associated with the oxidative-stress response, the most striking effect being to increase SodA synthesis in the $a c n B$ mutant. This could be caused by the elimination of a direct inhibitory interaction between apo-AcnB and $\operatorname{sod} A$ mRNA that normally modulates sodA expression. A transcription-translation system was therefore used to investigate the effects of apo-Acn proteins on SodA synthesis in vitro. With concentrations of aconitase approaching those occurring naturally in E. coli (5$10 \mu \mathrm{M})$ it was found that apo-AcnB lowered the de novo synthesis of SodA by up to twofold relative to Acn-free controls (33 and 28 c.p.m. at 0.2 and $2 \cdot 0 \mu \mathrm{M}$ apo-AcnB, respectively, compared to 56 c.p.m. in the Acn-free control), whereas SodA synthesis was slightly enhanced by apo-AcnA (70 and 75 c.p.m. at 0.2 and $2.0 \mu \mathrm{M}$ apoAcnA, respectively). These data suggest that the two apo-proteins have direct but opposite effects on the translation of sodA mRNA.

\section{DISCUSSION}

The present work was motivated by the observation that the apo-Acn proteins of $E$. coli are post-transcriptional regulators of Acn synthesis and by the suggestion that they might also function more widely by mediating a novel and rapidly reacting component of the bacterial oxidative response, based on the oxidative disassembly of their iron-sulphur clusters and modulating interactions with the transcripts of relevant genes (Tang $\&$ Guest, 1999). This proposal was supported by the finding that acn mutants are particularly susceptible to oxidative-stress reagents and by the observation that aerobic cultures of $a c n B$ have a high SodA content, indicating that they are in an oxidatively stressed condition. Hence, it is suggested that Acn proteins provide a protective mechanism that allows E. coli to withstand the basal endogenous level of oxidative stress associated with aerobic growth. By acting as the initial buffer against oxidative stress the release of iron from the aconitase proteins represents a potential source of danger because the combination of $\mathrm{H}_{2} \mathrm{O}_{2}$ and iron generates highly reactive hydroxyl radicals that cause a wide range of DNA lesions (Keyer \& Imlay, 1996; Nunoshiba et al., 1999). Conversely, there is evidence indicating that growth in an iron-enriched medium can partially compensate for the lack of SodA activity in $E$. coli (Benov \& Fridovich, 1998). Moreover, it has been suggested that the oxidation of the $[4 \mathrm{Fe}-4 \mathrm{~S}]$ clusters by superoxide and the subsequent reassembly of the damaged clusters facilitated by iron enrichment could spare other targets from superoxide attack and still maintain $[4 \mathrm{Fe}-4 \mathrm{~S}]$-enzyme activities at levels that continue to support metabolism. If the aconitase proteins are particularly susceptible to superoxide attack, and the iron released from them is not available for Fenton chemistry, the continuous process of $[4 \mathrm{Fe}-4 \mathrm{~S}]$ cluster assembly and superoxide-mediated destruction could act as a sink for the superoxide produced as a consequence of aerobic metabolism (Messner \& Imlay, 1999); thus the absence of this buffer could contribute to the enhanced sensitivity of the acn mutants to oxidative stress.

The major exponential-phase aconitase, AcnB, appears to be particularly important for neutralizing the effects of superoxide generated during aerobic growth and in resisting $\mathrm{H}_{2} \mathrm{O}_{2}$. In contrast, the stationary-phase SoxRSregulated enzyme, AcnA, seems to play a lesser role in aerobic exponential-phase cultures, as expected from the observed patterns of transcriptional regulation of the two acn genes (Cunningham et al., 1997). Potential targets affected by the absence of aconitase-mediated neutralization of reactive oxygen species were revealed by proteomic analysis. These targets include SodA and TrxB, which both have well-characterized roles in resisting oxidative stress, indicating that the accumulation of reactive oxygen species in the absence of Acn is sufficient to trigger a response. However, the degree of stress generated by the acn lesions was not sufficient to induce expression of the $\mathrm{OxyR}$ regulon because the catalase activities $\left[0.075\right.$ to $\left.0.081 \mathrm{U}\left(\mathrm{mg}^{2} \text { protein }\right)^{-1}\right]$ and the amounts of KatG protein were unaffected in the $a c n$ mutants relative to the parental strain. Other consequences of the acn lesions were reduced levels of translation (RpsA, AsnS) and chaperone (GroEL, DnaK, Tig) proteins, and increased amounts of proteins of the citric acid cycle (ODH, SCS), substrate transport (OppA), acid stress (HdeB) and possibly DNA repair (YggX). Many of the corresponding genes have recently been reported to respond to the imposition of $\mathrm{MV}$ and/or sodium salicylate stress (Pomposiello et al., 2001). The up-regulation of components of the ODH complex and of SCS is interesting because these enzymes 
are major control points in switching the citric acid cycle from its aerobic, mainly catabolic, role to its anaerobic, non-cyclic and mainly anabolic, role. The acn lesions studied here would clearly impair or abolish carbon flux through the citric acid cycle and lead to depletion of the NADH:NADPH pools, which would be further depleted by the presence of MV. The up-regulation of ODH and SCS might represent misguided attempts to restore the flow of carbon through the citric acid cycle, thereby generating reducing equivalents.

The regulation of $\operatorname{sod} A$ expression is complex because the activity of the $\operatorname{sod} A$ promoter is modulated by at least five transcription factors [SoxRS, Fur, FNR (fumurate and nitrate reduction regulator), ArcA and IHF (integration host factor)] (Compan \& Touati, 1993). Expression is mainly controlled by SoxRS, which activates $\operatorname{sod} A$ expression in response to superoxide, whereas FNR, ArcA, Fur and IHF repress expression in response to oxygen and iron availability. This combination of regulators allows sodA expression to be geared to the degree of stress posed by the simultaneous exposure to iron and oxygen (superoxide), which can lead to the production of very toxic hydroxyl radicals. The present studies suggest another seemingly more immediate regulatory mechanism that controls SodA synthesis at the translational level. It would now appear that the aconitases can act both positively (AcnA) and negatively $(\mathrm{AcnB})$ to control translation of the $\operatorname{sod} A$ message. This dual control may facilitate fine-tuning with respect to growth phase and environmental stress. Analysis of the $\operatorname{sod} A$ transcript for sequences/structures resembling those associated with Acn-binding to $a c n$ mRNA has revealed only one short sequence, ACGCG, located in the 5' UTR (12 bases downstream of the transcriptional start site and 42 bases upstream of the start codon) of the sodA transcript which is present in the 3' UTRs of the two acn transcripts (Tang \& Guest, 1999). The absence of stem-loop structures resembling those identified in the $3^{\prime}$ UTRs of the $a c n A$ and $a c n B$ transcripts in $\operatorname{sod} A$ suggests that interactions between apo-Acn proteins and sodA may be distinct from those observed previously, but the effects on translation of $\operatorname{sodA}$ occur at similar concentrations to those required for regulation of acn translation (Tang \& Guest, 1999).

The enhanced expression of sodA in E. coli acn mutants is a clear indication that by acting as a sink for superoxide and by regulating $\operatorname{sod} A$ translation the Acn proteins serve as a first line of defence against the superoxide produced during aerobic metabolism. Thus, it is suggested that the status of the $[4 \mathrm{Fe}-4 \mathrm{~S}]$ cluster of $A c n B$ reflects the degree of oxidative stress normally experienced by E. coli. When oxidative stress is low AcnB might serve both as an aconitase and as a repressor of $\operatorname{sod} A$ translation, but as the level of stress increases the more stable AcnA protein takes over the metabolic function of $A c n B$. This response is sufficient to manage the superoxide stress without resorting to enhanced SodA production, and thus remaining apo-AcnB continues to block sodA translation and destabilize the $\operatorname{sod} A$ transcript. If the level of superoxide stress con- tinues to threaten the bacterium the SoxRS system is activated and transcription of $\operatorname{sod} A$ is enhanced. Consequently, the intracellular concentration of the $\operatorname{sod} A$ transcript increases relative to the concentration of $A c n B$ and in combination with the generation of apoAcnA, through the use of AcnA [4Fe-4S] clusters as superoxide sinks, the sodA transcript is stabilized and translation is enhanced to detoxify remaining superoxide.

\section{ACKNOWLEDGEMENTS}

We thank the Aberdeen Proteome Facility for mass spectrometry and The Wellcome Trust for a project grant (060940).

\section{REFERENCES}

Aiba, H., Adhya, S. \& De Crombrugghe, B. (1981). Evidence for two functional gal promoters in intact Escherichia coli cells. J Biol Chem 256, 1905-1910.

Alen, C. \& Sonenshein, A. L. (1999). Bacillus subtilis aconitase is an RNA-binding protein. Proc Natl Acad Sci US A 96, 1041210417.

Beinert, H., Kennedy, M. C. \& Stout, C. D. (1996). Aconitase as iron-sulfur protein, enzyme and iron-regulatory protein. Chem Rev 96, 2335-2373.

Benov, L. \& Fridovich, I. (1998). Growth in iron-enriched medium partially compensates Escherichia coli for the lack of manganese and iron superoxide dismutase. J Biol Chem 273, 10313-10316.

Boni, I. V., Artamonova, V. S. \& Dreyfus, M. (2000). The last RNA-binding repeat of the Escherichia coli ribosomal protein S1 is specifically involved in autogenous control. J Bacteriol 182, 5872-5879.

Bradbury, A. J., Gruer, M. J., Rudd, K. E. \& Guest, J. R. (1996). The second aconitase (AcnB) of Escherichia coli. Microbiology 142, 389-400.

Carlioz, A. \& Touati, D. (1986). Isolation of superoxide dismutase mutants in Escherichia coli: is superoxide dismutase necessary for aerobic life? EMBO J 5, 623-630.

Compan, I. \& Touati, D. (1993). Interaction of six global transcription regulators in expression of manganese superoxide dismutase in Escherichia coli K-12. J Bacteriol 175, 1687-1696.

Cunningham, L., Gruer, M. J. \& Guest, J. R. (1997). Transcriptional regulation of the aconitase genes $(a c n A$ and $a c n B)$ of Escherichia coli. Microbiology 143, 3795-3805.

Gardner, P. R. \& Fridovich, I. (1992). Inactivation-reactivation of aconitase in Escherichia coli: a sensitive measure of superoxide radical. J Biol Chem 267, 8757-8763.

Gardner, P. R., Costantino, G., Szabo, C. \& Salzman, A. L. (1997). Nitric oxide sensitivity of the aconitases. J Biol Chem 272, 25071-25076.

Gifford, C. M. \& Wallace, S. S. (1999). The genes encoding formamidopyrimidine and MutY DNA glycosylases in Escherichia coli are transcribed as part of complex operons. J Bacteriol 181, 4223-4236.

Greenberg, J. T., Monach, P., Chou, J. H., Josephy, D. \& Demple, B. (1990). Positive control of a global antioxidant defense regulon activated by superoxide generating agents in Escherichia coli. Proc Natl Acad Sci U S A 87, 6181-6185.

Gruer, M. J. \& Guest, J. R. (1994). Two genetically-distinct and differentially-regulated aconitases (AcnA and AcnB) in Escherichia coli. Microbiology 140, 2531-2541. 
Gruer, M. J., Artymiuk, P. J. \& Guest, J. R. (1997a). The aconitase family: three structural variations on a common theme. Trend Biochem Sci 22, 3-6.

Gruer, M. J., Bradbury, A. J. \& Guest, J. R. (1997b). Construction and properties of aconitase mutants of Escherichia coli. Microbiology 143, 1837-1846.

Hentze, M. W. \& Kuhn, L. C. (1996). Molecular control of vertebrate iron metabolism: mRNA-based regulatory circuits operated by iron, nitric oxide and oxidative stress. Proc Natl Acad Sci US A 93, 8175-8182.

Holland, R. D., Duffy, C. R., Rafii, F., Sutherland, J. B., Heinze, T. M., Holder, C. L., Voorhees, K. J. \& Lay, J. O. (1999). Identification of bacterial proteins observed in MALDI TOF mass spectra from whole cells. Anal Chem 71, 3226-3230.

Jordan, P. A., Tang, Y., Bradbury, A. J., Thomson, A. J. \& Guest, J. R. (1999). Biochemical and spectroscopic characterisation of Escherichia coli aconitases (AcnA and AcnB). Biochem J 344, 739-746.

Keyer, K. \& Imlay, J. A. (1996). Superoxide accelerates DNA damage by elevating free-iron levels. Proc Natl Acad Sci U S A 93, 13635-13640.

Lennox, E. S. (1955). Transduction of linked genetic characters of host by bacteriophage P1. Virology 1, 190-206.

Messner, K. R. \& Imlay, J. A. (1999). The identification of primary sites of superoxide and hydrogen peroxide formation in the aerobic respiratory chain and sulfite reductase complex of Escherichia coli. J Biol Chem 274, 10119-10128.

Miller, J. H. (1972). Assay of $\beta$-galactosidase. In Experiments in Molecular Genetics, pp. 352-355. Cold Spring Harbor, NY : Cold Spring Harbor Laboratory.

Nunoshiba, T., Obata, F., Boss, A. C., Oikawa, S., Mori, T., Kawanishi, S. \& Yamamoto, K. (1999). Role of iron and superoxide for generation of hydroxyl radical oxidative DNA lesions, and mutagenesis in Escherichia coli. J Biol Chem 274, 34832-34837.

Pomposiello, P. J., Bennik, M. H. J. \& Demple, B. (2001). Genomewide transcriptional profiling of the Escherichia coli responses to superoxide stress and sodium salicylate. J Bacteriol 183, 3890-3902.
Prodromou, C., Haynes, M. J. \& Guest, J. R. (1991). The aconitase of Escherichia coli: purification of the enzyme and molecular cloning and map location of the gene (acn). J Gen Microbiol 137, 2505-2515.

Richarme, G. \& Caldas, T. D. (1997). Chaperone properties of the bacterial periplasmic substrate-binding proteins. J Biol Chem 272, 15607-15612.

Sambrook, J., Fritsch, E. F. \& Maniatis, T. (1989). Molecular Cloning: a Laboratory Manual, 2nd edn. Cold Spring Harbor, NY : Cold Spring Harbor Laboratory.

Silhavy, T. J., Barman, M. L. \& Enquist, L. W. (1984). Experiments with Gene Fusions. Cold Spring Harbor, NY: Cold Spring Harbor Laboratory.

Skouv, J., Schnier, J., Rasmussen, M. D., Subramanian, A. R. \& Pedersen, S. (1990). Ribosomal protein S1 of Escherichia coli is the effector for the regulation of its own synthesis. J Biol Chem 265, 17044-17049.

Somerville, G., Miloryak, C. A. \& Reitzer, L. (1999). Physiological characterization of Pseudomonas aeruginosa during exotoxin A synthesis: glutamate, iron limitation, and aconitase activity. $J$ Bacteriol 181, 1072-1078.

Tang, Y. \& Guest, J. R. (1999). Direct evidence for mRNA binding and post-transcriptional regulation by Escherichia coli aconitases. Microbiology 145, 3069-3079.

Wilson, T. J. G., Bertrand, N., Tang, J.-L., Feng, J.-X., Pan, M.-Q., Barber, C. E., Dow, J. M. \& Daniels, M. J. (1998). The $r p f A$ gene of Xanthomonas campestris pathovar campestris, which is involved in the regulation of pathogenicity factor production, encodes an aconitase. Mol Microbiol 28, 961-970.

Yoshida, T., Ueguchi, C., Yamada, H. \& Mizuno, T. (1993). Function of the Escherichia coli nucleoid protein, H-NS: molecular analysis of a subset of proteins whose expression is enhanced in an hns deletion mutant. Mol Gen Genet 237, 113-122.

Received 12 October 2001; revised 4 December 2001; accepted 7 December 2001. 